\title{
ENGLISH FOR EUROPEAN COMMUNICATION AND TOURISM: FOCUS ON PRAGMATIC COMPETENCE
}

\author{
AGATA KLIMCZAK-PAWLAK \\ University of Warsaw \\ agata.klimczak.pawlak@uw.edu.pl
}

\begin{abstract}
Pragmatic competence in L2 English is claimed here to be crucial for successful communication in a variety of communicative contexts across Europe. However, due to language background, cultural and identity differences among users of English, there is a need for reflection and data-driven examination of how the language is used in specific situations. This paper adopts a cross-cultural perspective on the study of the use of English in the European Union with focus on its role in tourism. The role of English as the language of communication in Europe is discussed, followed by a proposal as to the way in which its actual usage can be studied. The data-driven approach to pragmatic behavior is advocated as the basis for the development of pragmatic competence in learners of English with focus on those who wish to engage in tourism.
\end{abstract}

Keywords: Pragmatic competence, English for European Communication, English for tourism, L2 pragmatics, speech acts

\section{Introduction}

Tourism and foreign languages go together like a horse and a carriage. One without the other is not what it should be. Without foreign language knowledge travelling and communicating with foreigners is potentially a road full of potholes. This article claims that the potholes can be identified and avoided with the development of pragmatic competence in teaching English for European communication.

According to Eurostat data (2018) in 2016 in the European Union only 35.4 $\%$ of adults (aged between 25 and 64) admitted to not knowing a single foreign language, while the other $64,6 \%$ reported they knew one (35.2\%), two $(21.0 \%)$, three or more foreign languages $(8.4 \%)$. Although the ideal would be for everyone to know several languages, the reality is that the most widely spoken and learnt language in the EU is English (Eurostat Foreign language learning statistics, 2018). In 2016 in 17 member states 80\% to $100 \%$ primary school students, and an astounding 94.0\% of upper secondary students learnt English. Perhaps unsurprisingly, more than 9 out of every 10 Latvian, Polish, French and Croatian primary school children learnt this language. The importance of 
English cannot be undermined and anyone planning on pursuing a career in tourism is most probably learning it. According to Eurostat's Tourism Statistics (2018) an estimated 12.7 million people were employed in 2.4 million enterprises be-longing to the tourism industries in 2017. Referring back to the metaphor of language and tourism going together like a horse and a carriage one cannot overlook a practical issue. Not all carriages are suitable for every horse, not all mechanisms are equally ingenious. If the English learnt and taught in different EU states is not the same but different due to e.g. culturally-specific use of English (i.e. pragmatic transfer), then instead of facilitating communication it may impede it. In other words, the carriages may seem to work perfectly, but may have technical differences impeding the process of transporting messages, which means that even though on the surface interlocutors may share the knowledge of lexis and grammar of English, they may differ in their use of that language. This paper focuses on the role of English in Europe. The key question to be explored is the nature of English that could serve as a tool for European communication and which therefore would best suit the needs of tourists across Europe as well as tourism professionals in Europe.

Standard English as used in the UK or any other English-speaking country is claimed here not to satisfy the needs of successful communication within the EU for both cultural and identity reasons, nor does it reflect its actual usage (Klimczak-Pawlak 2014). An alternative option is thus explored: a usage-based variety tailored to the specific needs of professions. This approach rests on the recognition of importance of cross-cultural communication, mutual understanding, cross-linguistic politeness norms and pragmatic competence in language learning. The present paper explores the above issues by first briefly discussing language diversity in the European Union, then moving on to European culture and identity, English for European Communication and, finally, the role of pragmatic competence in teaching English for tourism.

\section{Languages in the European Union}

The European Union is an evolving, growing body, bringing together economically, politically, and above - all culturally and linguistically diverse countries, an unprecedented attempt to unite people of different religions, beliefs, values, different national identities and interests. It is an attempt to create a shared identity and culture, an attempt to foster better understanding, to cultivate respect for "the other", to promote cooperation and intercultural ties.

The linguistic diversity of the European Union is impressive. At the moment there are twenty-four official languages of the EU, and it has been estimated by the European Commission (2004), that there are up to fifty million speakers of over a hundred and fifty minority and regional languages. The EU promotes the 
acceptance and pride in diversity advocating its citizens to embrace and respect the linguistic and cultural differences:

It is the diversity that makes the European Union what it is, not a 'melting pot' in which differences are rendered down, but a common home in which diversity is celebrated, and where our many mother tongues are a source of wealth and a bridge to greater solidarity and mutual understanding. (European Commission 2005: 2)

The motto of the EU "Unity in Diversity" clearly portrays its philosophy. In the Charter of Fundamental Rights of the European Union one can read that " $[\mathrm{t}] \mathrm{he}$ Union shall respect cultural, religious and linguistic diversity" (2000: Article 22), and the main aim of the Council of Europe is to promote plurilingualism among European citizens for the purpose of spreading tolerance and preventing xenophobia. Seeing as "[1]inguistic diversity is one of the EU's defining features" and "[r]espect for the diversity of the Union's languages is a founding feature of the European Union" (Commission of the EC 2003: 12) the Council of Europe created a Language Policy Division, which aims at promoting plurilingualism and its "[p]rojects are primarily concerned with the development of language education policy with a particular emphasis on plurilingualism, common European reference standards, and language education rights and policies" (Language Policy Division brochure). However, as Phillipson (2006:346) notes "[1] anguage policy is torn between top-down pressures to maintain the position of national languages, and bottom-up pressures to secure linguistic diversity and the implementation of language rights". As it is up to each member state to foster plurilingualism and to decide on matters connected to the implementation of language policies "[i]t is, therefore, no surprise that European language policy is developing at different speeds and even in different directions, the inevitable gainer in such a situation being international English" (Mar-Molinero and Stevenson 2006: 240).

This struggle between the want of building a greater union and the want of maintaining individualism is a struggle without an easy solution. Europe's wealth of linguistic diversity as a strength is weakened by practical reasons: by a need for a common language which would facilitate quick and effective communication. The effort of the EU to maintain a balance of power and importance of different languages goes against a natural tendency for a community to use a common means of getting their message across. 


\section{European culture and identity}

The question of what it means to be a European is often asked. The ideal European, a citizen of the European Union, knows languages; he or she is plurilingual and has a high level of intercultural competence. Such a combination enables her or him to communicate easily with other Europeans. The ideal is for each person to know at least two languages apart from their native language. However, even though knowledge of different languages and cultures is definitely enriching, if a person from Spain speaks Portuguese and French and a person from Poland speaks German and Slovak, then one might wonder how their knowledge of languages brings them closer even to their neighbours and whether contributes to mutual understanding.

There are 24 official languages in the EU which means that there is an astonishing number of combinations of language pairs that one may choose from. With such an array of combinations the probability of meeting a person with whom one would share the same pair of foreign languages is relatively small. Having said that, some languages are more popular than others and are more often learnt; Eurobarometer data suggests English, German and French are the top three choices among those wanting to learn a foreign language. If we assume one of these languages is chosen by each European, the number of combinations goes down considerably. A smaller number of combinations means a greater probability that both interlocutors would have a common language in their repertoires. However, still, it would be most convenient for all Europeans to be able to communicate in one language.

Along with learning a language one learns much more, one also learns a new way of conceptualizing the world and possibly the culture of the users of that language. One of the well-known claims, viz. Sapir and Whorf Hypothesis (Whorf 1956) is that language determines the way we think, and therefore, when we learn a foreign language we also learn a new way of thinking and perceiving the reality. Quite often foreign language learners notice that with a new language they assume a new identity and behave differently to the way they behave when speaking their mother tongue. With that in mind one may ask once again how the ideal European plurilingualism helps Europeans to communicate; undeniably it allows them to know more about different ways of perceiving the world and about cultural differences but does it truly help Europeans know each other better, create bonds and common identity?

The question regarding the character of European identity is a highly debated one (e.g. Risse 2004, 2010, Grundy and Jamieson 2007, Caporaso and Kim 2009) and it is clear that there is no consensus as to what being European means. Caporaso and Kim (2009) notice that when trying to define a European identity, a distinction is often made between civic and cultural identity (Bryter 2005), personal and social identity (Breakwell 2004), and patriotism and nationalism (Li and Brewer 2004); as well as between identity as coherence and identity as subjective awareness (Caporaso and Kim 2009). 
Among others, European identity can be viewed from the post-nationalism perspective, cosmopolitanism, and the dialogic view of culture. Some scholars, as Archibugi, believe that the EU is "the first international model which begins to resemble the cosmopolitan model" (Archibugi 1998: 219). Cosmopolitanism with connection to European identity has been ascribed many meanings. Vertovec and Cohen (2002 in Pichler 2008) define cosmopolitanism as "a condition, a philosophy or world view; political cosmopolitanism in terms of international cooperation as well as multiple affiliations; attitudes or dispositions; and practices and competences" (Vertovec and Cohen quoted in Pichler 2008: 1109). According to Pichler (2008), cosmopolitanism in its new form is characterised by the ability to recognise both similarities and differences between people, to maintain multiple identities and affiliations while simultaneously maintaining individualism. Pichler notes that in the EU "boundaries of how much difference is acceptable and where similarity ends are constantly negotiated, as can be seen in Council meetings, the documents of the EU (e.g. the constitution), community law (majority rule) and the debate about Turkey's potential accession" (Pichler 2008: 1110). Eurobarometer 64.2 (European Commission 2005) data allowed Pichler to conclude that most respondents with cosmopolitan affiliations, in contrast to these with more national affiliations, are less afraid of the EU threatening their national culture, language, heritage and identity, and that they are more likely to support European integration.

Attitudes towards the European Union have been also documented by Eurobarometers. Eurobarometer 73 (European Commission 2010) data indicate that more than half of EU citizens (53\%) of all 27 member states felt their countries had benefited by being a part of the EU. The four top answers to the question on what the EU means to you were freedom to travel, study and work anywhere in the EU (45\%), Euro (40\%) and peace (24\%), and waste of money $(23 \%)$. Only $12 \%$ of respondents pointed to loss of cultural identity.

Identity is established by our behaviour, the way we dress, and by our use of language. Our place of birth, our family, the socioeconomic group we belong to are all relevant factors. Our identity changes throughout our life through interaction with those around us. Additionally, one person may have several different identities as we all modify our behaviour depending on the situation, we constantly enter and exit different roles, and sometimes a specific context may require us to activate conflicting identities. The language we use and the way we use it plays an important role in the construction, shift and display of our different identities.

The relationship between culture and language is complex. Relativism suggests the existence of as many worlds as many means of their expression. The claim is that the way we describe the world affects the way we see it. Each culture and each society may have different values and assumptions about the reality shaped by the language they use. Differences regarding, among others, the existence or lack of various concepts, words, writing and counting systems, 
and grammars all point to different ways of categorising the world, of experiences the speakers of these languages have.

\section{Learning English for European Communication}

Learning a foreign language means learning its vocabulary, its grammar, pronunciation, developing the skills of speaking, reading and writing and quite significantly - the rules of language use in context. When we learn a language which "belongs" to a specific country (e.g. Polish) we needs to learn the specificity of the use of that language including how to use it in different social contexts, politeness norms, conventions, forms of address, social relationships, appropriateness of specific language use and behaviour. The task might not be easy but the reference point is clear. Need be, one may turn to books on linguistic and non-linguistic etiquette. Resources are a click away. When learning English, however, there are several decisions one needs to make-is he or she learning this language for the purpose of communicating in a specific English speaking country or for intercultural communication? Those who choose to tie their professions with tourism will undoubtedly aim to become proficient intercultural communicators with a high level of communicative competence, and particularly pragmatic competence.

Out of many definitions of pragmatics it is David Crystal's (2008) one that is often cited. As he puts it, pragmatics is "the study of language from the point of view of the users, especially of the choices they make, the constraints they encounter in using language in social interaction, and the effects their use of language has on the other participants in an act of communication" (Crystal 2008: 379) and that it "focuses on an 'area' between semantics, sociolinguistics and extralinguistic context; but the boundaries with these other domains are as yet incapable of precise definition" (379). Both interlocutors are therefore stressed with regard to their choices, constraints and effect that their utterances have on one another in the process when they co-construct and deconstruct meaning in interaction. Pragmatic competence is then the "the ability to communicate your intended message with all its nuances in any socio-cultural context and to interpret the message of your interlocutor as it was intended" (Fraser, 2010:15). Kecskes (2013) argues that users of a foreign language have at least two sets of linguistic and non-linguistic customs. When a learner knows she is learning e.g. English with a specific aim of communicating with culturally and linguistically diverse people, she knows she cannot rely solely on target language norms and she knows there is risk of miscommunication due to differences in language use. Therefore, she should be aware of how safe, or how risky her utterances are in terms of the expected result. In a sense, intercultural communication is akin to risk management and one needs a highly developed pragmatic competence in order to assess risk adequately. 
For successful interactions one can clearly see the obvious importance that pragmatic competence holds within the communicative competence, and yet it is rarely developed in foreign language classroom. Bardovi-Harlig (2017) suggests it may be due to insufficient curriculum planning and lack of materials which would be focused specifically on pragmatics.

One way in which learners can be aided in the development of their pragmatic competence is by introducing them to awareness-raising activities. This idea is far from new. Schmidt proposed teaching pragmatics through consciousness raising back in 1983 and since then it has been repeatedly shown that indeed sensitizing learners to sociopragmatics, often through metapragmatic instruction, positively influences their pragmatic competence. Some activities include exposing learners to cross-cultural examples, discussing with them L1 and L2 cultures along with sociopragmatic similarities and differences, politeness norms, expectations, un/acceptable directness etc. (e.g. FélixBrasdefer and Cohen 2012; Haugh and Chang 2015; Rose 2005). Van Compernolle (2014) proposed the marriage of sociocultural theory and the teaching of pragmatics through social practices. The majority of literature on the development of linguistic politeness in speech act realisation in English as a foreign language (e.g. Félix-Brasdeer and Cohen 2012; Rose 2005; Tatsuki and Houck 2010) focuses predominantly on linguistic means of softening speech acts (e.g. requests, refusals, complaints). Yet as we know, not all European EFL users soften their utterances and, what is more, doing it may feel very artificial to them. Félix-Brasdefer and Mugford (2017) point to the need of teaching both polite and impolite behaviour in a foreign language classroom and propose a four step process where at the beginning the focus is on awareness raising activities, then on pragmatic input and reflection on im/politeness, identification of contextual and co-textual factors; the third step centres around raising pragmalinguistic awareness of linguistic features of im/polite practices; in the final, fourth stage teachers are encouraged to focus on bringing the knowledge gained in the previous steps into practice.

\section{English for European Communication: problems and possible solutions}

Deciding on English as the language used for communication in Europe may seem an obvious solution, but it is far from being so. On the one hand, there are historical reasons for opposing English in Europe (particularly strong in France). On the other hand, there are arguments against forcing the standard as used in, e.g. the United Kingdom and for accepting modified versions of English in teaching.

One could suggest that English as a Lingua Franca (ELF) is already the reality and it might be easiest to continue observing and characterising ELF to then start teaching it. Seidlhoffer and Jenkins were catalysts in the discussion of the role and characteristics of English in Europe. Focusing on intelligibility, they 
proposed that English used by non-native speakers could be viewed as a largely independent, new variety with its own characteristics in lexico-grammar (Seidlehoffer 2005) and phonology (Jenkins 2000). Used for transactional purposes ELF was proposed to contain elements of traditionally incorrect English, such as e.g. the lack of articles, or modified word formation (e.g. touristic) However important their contribution is, ELF is not and will never be the solution to the European linguistic dilemma for several reasons. Firstly, ELF it comes with a "baggage". It can be viewed as being a negatively stereotyped "pidgin", placing its speaker in a disadvantageous, vulnerable position. Moreover, the British Council's work cannot be expected to be undone quickly; most teachers and learners have a deep belief in the superiority of British English over other varieties of English, a devotion to the "purity" of Queen's English and the need to pursue a native-like model. The idea that now, based on researchers' observations teachers should teach ELF with its grammar, spelling and pronunciation traditionally seen as incorrect, cannot be realistically expected to be embraced by teachers. In spite of what its proponents may claim, ELF does bear close similarity to fossilised interlanguage with its phonological and lexicogrammatical features. The focus on form overshadows the focus on culture in ELF. Language is the main carrier of culture and therefore it seems baffling that a language that could potentially be used as a main means of communication Europeans would not provide means for expressing the diversity and cultural heritage of Europe without running the risk of being treated as inferior due to the linguistic forms used in communication. Europe is highly hierarchical and therefore it should not be surprising that ELF faced a wave of criticism; simplifying English, an already fairly easy language and embracing this "simplified" meaning, in fact incorrect language for the less capable, provokes the reactions of disbelief and anger (see the discussion in Dziubalska-Kołaczyk and Przedlacka 2005).

Teaching ELF with its simplified lexico-grammar and phonology does not seem to be a sensible solution for Europe, where the level of proficnecy in English reached by learners of English in schools is already very high. However, observing the linguistic and pragmatic behaviour of proficient European L2 English users (Klimczak-Pawlak 2014) pints to the fact that it is in the area of specific speech act realization that communicatively sensitive differences exist. Further observation of situation-specific language behaviours of the Europeans in English would allow us to establish patterns of language use from a pragmatic perspective Undoubtedly, Europeans do share a lot of behaviours. By studying what various European L2 English speakers believe to be appropriate and polite, by looking at speech act realization patterns, we can note how similarly L2 English users from different European linguistic and cultural backgrounds use English. Based on this we could establish which pragmatic L2 English behaviours are relatively "safe" from the potential of misunderstanding. The assumption behind this argument is that pragmatic behaviour which is most widely shared is the safest. By observing the use of politeness strategies, speech 
act realization patterns etc., we would be able to establish a core of "safe" strategies for performing various linguistic actions. English for European communication would therefore combine the linguistic code: the grammar and lexis of British English and European pragmatics, the European way English is used when it comes to politeness norms, construction and negotiation of meaning.

Studying the way advanced speakers from different European countries produce, for example, a range of speech acts would suggest what is most common for all. However, when teaching English for European Communication it would be crucial to stress that those strategies listed in the core are to serve as a reference and that it is by no means incorrect to perform e.g. a speech act of apologising in a given context using other strategies than those listed in the core. All Europeans should be free to perform any speech act in any way they wish, however, it is crucial that they make a conscious decision and that they know what strategies are in the core should they find themselves in a situation needing clarification and in which they would benefit from falling back on those strategies. A very important part of English for European Communication would be awareness raising with regards to intercultural communication, possible communication problems and solutions.

One solution to this problem would be to learn politeness norms of the British and try to teach and learn politeness and appropriateness as seen by our European native speakers of English. However, the problem with this is obvious. Why should a language and culture of one-member state be more important than any other? Why should we use native British English speaker model as a yard stick? These are just the two, most obvious reasons why relying on British English standards for politeness is no a viable option.

Analysing, for example, speech act production, e.g. how L2 English users from European countries apologise, refuse, request etc., we can learn about the differences and similarities in their strategy choice, attitude towards hierarchy and social distance. By comparing how native speakers of various member states e.g. apologise in L2 English we can predict what elements of what speech acts may prove to be problematic. If, for example in the same situation a native speaker of one language believes one should apologise profoundly, using a variety of strategies, and another speaker, from a different cultural and linguistic background believes a simple "sorry" would suffice, we may predict that there might be a problem. Even when we attain a high proficiency in a foreign language we might differ in our pragmatic competence, in the way we use that language and how we rate politeness and appropriateness of different behaviours. What might be appropriate linguistic behaviour in English for a German might not be seen as such by a Spaniard.

The question which now requires an answer is how this core of English for European Communication may be established. Since the core is to be based on the pragmatic behaviour of proficient European L2 English speakers it is obvious that investigation into the pragmatic behaviour of this particular group 
should be carried out. By noting how such users of English, coming from different linguistic and cultural backgrounds perform, e.g. various speech acts it is be possible to distinguish what pragmatic behaviour is common for them and what is not (see e.g. Klimczak-Pawlak 2014). Ideally a representative, comparable number of participants from each member state with similarly high proficiency in English would take part in the study of European for English Communication. Additionally, it would also be ideal if a range of speech acts and politeness ratings were carried out.

\section{Researching European L2 English pragmatics - an investigation into L2 English apologies of Dutch, Macedonian, Polish, Slovak and British students}

The investigation into how groups of people from different cultural and linguistic backgrounds perform a variety of communicative acts requires an analysis of their L2 English output. The most obvious and fundamental questions which need to be considered are, firstly, which area of linguistic pragmatic behaviour to select for investigation, secondly, which groups of language users to focus on and, finally, how to collect data. This section presents an example of a study which aims to provide data on how users of L2 English produce meaning; the study investigates a specific speech act realization by selected groups of users in discourse completion tests.

When travelling abroad it may happen that we find ourselves in a situation requiring us to apologise. Be it an apology for bumping into someone, not understanding, for misinterpreting, or for any other transgression. Let us therefore, select the speech act of apologising for this analysis. The research question then pertains to the speech act of apologising. Naturally we apologise differently in different contexts, depending on who we are addressing, how severe the offence was and where we are we adjust what we say. We therefore take into consideration the different situations with varying power relations between the interlocutors.

Participants of this study are university students, who have been reported to be a very mobile group in the EU. It is estimated that in 2017 over 1.7 million students at the tertiary level enrolled to study in a country different than the one where they graduated from upper secondary education (Eurostat 2019). With a shared language - English, and with more opportunities to travel and study abroad than ever before, students are also more than ever before susceptible to misunderstandings, misconstruction of their interlocutors' intentions and they may draw wrong and hurtful generalisations which instead of uniting the EU may have the opposite effect. It seems then of paramount importance to closely analyse the language they produce. The participants are 89 Polish, 74 Macedonian, 56 Slovak, 20 Dutch and 7 English students. 
Data collection methods most often used in L2 pragmatic production research are discourse completion tests (DCTs), role plays and recording of authentic data (Culpeper, Mackey, Taguchi 2018). As the purpose of this study is to investigate not spontaneous speech but consciously constructed utterances, the participants were given ample time to fill out a written discourse completion test during class at their universities. The focus here is on what they believe is an appropriate reaction in the described contexts and not on what the participants think they would actually say.

The responses provided by the participants were coded for the following 8 main strategies: 1) An expression of an apology (use of IFID); 2) An acknowledgement of responsibility (RESP); 3) An explanation or account of the situation (EXPL); 4) An offer of repair (REPR); 5) A promise of forbearance (FORB); 6) Internal intensifiers (within direct or indirect apology formulas); 7) Phatic Communion; and 8) No Apology.

For the purpose of this analysis we limit our investigation to two scenarios which are especially relevant to university student experiences, i.e. interactions involving a lecturer: 1) You are in a cafeteria with your lecturer discussing your project. When reaching for your cup of coffee you accidentally knock it over and it spills over the lecturer's shirt. What do you say?; 2) You borrowed a book from your university professor and you were supposed to return it today but forgot to bring it. What do you say to the professor?

The results were tested for statistical significance using a t-test between collected national samples with the $5 \%$ chance probability level accepted as the minimum for significance of the difference between the means. The results of the t-test are presented in the table below. Statistical significance can be observed in the use of the "acknowledgement of responsibility" and "offer of repair" strategies. The test found the highest statistical significance in the relationship between Polish and Macedonian respondents, as well as Dutch and Macedonian in their use of the "acknowledgement of responsibility" strategy. Highest statistical significance is marked by 3 stars corresponding to the chance probability level smaller than $0.1 \%$. The same strategy presents statistical difference at the $1 \%$ (marked by 2 stars) in use between Slovak and Dutch respondents. High statistical significance can also be noticed in the relation between Polish and Macedonian respondents in their preference of the "offer of repair" strategy, moreover, statistical significance is reached in the relationship between them in regards to "promise of forbearance". 


\begin{tabular}{|c|c|c|c|c|c|c|c|c|c|c|}
\hline & IFID & RESP & EXPL & REPR & FORB & $\begin{array}{l}\text { INTERNAL } \\
\text { INTENSIFI } \\
\text { ERS }\end{array}$ & PC & NO & & \\
\hline POL-SVK & ns & ns & ns & $*$ & ns & ns & & Ns & & \\
\hline POL-MKD & ns & $* * *$ & ns & $* * *$ & $* *$ & ns & & Ns & & \\
\hline POL-NLD & ns & ns & ns & $* *$ & & ns & & Ns & & \\
\hline POL-UK & ns & ns & ns & ns & & ns & & Ns & & \\
\hline SVK-UK & ns & ns & ns & ns & ns & ns & & Ns & & \\
\hline SVK-MKD & ns & ns & ns & ns & ns & ns & & Ns & & \\
\hline SVK-NDL & ns & $* *$ & ns & ns & ns & ns & & Ns & $* * *$ & $\mathrm{p}<0,001$ \\
\hline NDL-MKD & ns & $* * *$ & ns & ns & ns & ns & & Ns & $* *$ & $\mathrm{p}<0,01$ \\
\hline NLD-UK & ns & ns & & ns & & ns & & Ns & * & $\mathrm{p}<=0,05$ \\
\hline MKD-UK & ns & ns & ns & ns & ns & ns & & Ns & ns & $\mathrm{p}>0,05$ \\
\hline
\end{tabular}

Table 1.

Clearly then, university students from different countries vary in their responses to the same situation. Given those differences the question arises as to how learners can be prepared for intercultural communication, how they can learn how to perform and respond to speech acts without fear of being misunderstood or causing a breakdown in communication. Undoubtedly, more data and more studies are needed to before practical application can be attempted.

In Europe we can talk of shared cultural and historical experiences and we can predict that the differences and similarities between the ways members of individual language-culture communities communicate in L2 English are not substantial, and that it would not be necessary to investigate speech act performance of advanced L2 English speakers from each member state. Based on previous research it seems possible to predict a certain degree of similarity in the tendency to rely on patterns of pragmatic behaviour. These cultural similarities or differences can be predicted to be reflected in the tendency for speakers from countries located geographically closer to each other to exhibit similarities in terms of their cultural and linguistic behaviour, with those similarities gradually growing weaker with larger distance, as suggested by the epidemiological approach to the study of culture. Another prediction with regards to the use of language can be based on the differentiation of individualist 
and collectivist cultures (Hofstede 1991). In turn Brown and Levinson (1987) distinguish between positive and negative politeness cultures, with individualist cultures claimed to exhibit a preference for negative politeness strategies, and collectivist for positive politeness strategies. Such a distinction is also said to correspond to the tendency to use indirect versus direct strategies (Wierzbicka 1985). These are just a few concepts which could be drawn from.

When specific areas of language use are catered for, the data for establishing the common core needs to reflect the actual language usage in real-life situations. The collection of such data is a pressing necessity for a comprehensive picture of situational language use across Europe. While the realistic data collected in a systematic way would be most useful for both academic and pedagogical purposes, the use of varied materials from across culture and language backgrounds can benefit teaching the use of English for cross-cultural communication in Europe.

\section{Concluding remarks}

By studying language use, among others, we learn how people perceive and create each other, what their belief system is, what they value. Every day when we talk to different people, we judge them, we create an opinion about them within seconds basing on their appearance, the way they talk and the content of their utterances. From early years we learn what is polite and appropriate linguistic and non-linguistic behaviour, how we should act in different situation, how to refuse, how to apologize to, e.g. our grandparent, a friend, a teacher or someone we do not know. It takes all of us many years to learn what behaviour is appropriate when depending on the goal we want to achieve. Since we are not born with this type of knowledge, and since we develop it through experience and education in our L1, it should not surprise anyone that when learning a foreign language it also takes time to learn what is polite and what is not and that it may take time for learners to create another set of rules of appropriate pragmatic behaviour. With varying cultural norms of politeness and with different cultures ascribing varying weight to social distance and power relations, with different strategies being preferred in various places around Europe, communication among non-native speakers of English may be challenging. Having one, shared English would make it more realistic to meet the challenges of multiculturalism and diversity. Tourism professionals, who need to master intercultural communication would benefit from such a variety. Ideally, learning English for European Communication should be combined with learning about different EU member states' cultures, values, traditions and languages.

A European intercultural communicator is sensitive to the varied norms and customs of their intercultural interlocutors, is aware of the potential differences of expression, potential pragmatic transfer, possible misunderstandings and he or 
she has the skills which would allow them to restore understanding should a breakdown in communication occur. For those reasons it is suggested here that EFL courses for all those who plan on learning English for the purpose of communicating in it in Europe, and especially for tourism professionals, should include the stages proposed by Félix-Brasdefer and Mugford (2017), and additionally: learning about European cultures and languages and etiquette, reflection on the strategies used by European users of English in various contexts, observing and analysing how users of English as a foreign language realise different speech acts and how they communicate in specific situations, as well as knowledge about the strategies for misunderstanding and conflict resolution, and risk assessment.

Recognising the significance of L2 pragmatics studies investigating patterns in cross cultural encounters by speakers coming from a number of linguistic and cultural backgrounds across Europe would contribute to a greater understanding of the specificity of the L2 English used by this group and more effective foreign language education. Adopting a European perspective, it would be possible to uncover shared patterns in the way such users of English from different member states construct and co-construct meaning and what they consider to be polite and impolite, which would all lead to the establishment of a set of safe strategies for performing various functions. It would allow all Europeans, but especially those who engage professionally in intercultural communication to develop skills and tools which would facilitate better understanding.

\section{References}

Archibugi, Daniele. 1998. Principles of Cosmopolitan Democracy. In: Re-imagining Political Community, ed. by D. Archibugi, D.Held \& M. Kölher. Oxford: Polity, 198-230.

Bardovi-Harlig, Kathleen. 2017. Acquisition of L2 pragmatics. In: The Routledge Handbook of Instructed Second Language Acquisition, ed. by S. Leowen, \& M. Sato. London: Routledge, 224 - 245. https://doi.org/10.4324/9781315676968-13

Breakwell, Glynis M. 2004. Identity Change in the Context of the Growing Influence of European Union Institutions. In: Transnational Identities. Becoming European in the EU, ed. by R. K. Herrmann, T. Risse \& M. B. Brewer. Oxford: Rowman \& Littlefield, 25-39.

Bruter, Michael. 2005. Citizens of Europe? The Emergence of a Mass European Identity. Basingstoke, Hampshire: Pelgrave Macmillan. https://doi.org/10.1057/9780230501539_7

Brown, Penelope, Steven Levinson. 1987. Politeness. Some universals in language usage. Cambridge: Cambridge University Press. https://doi.org/10.1017/CBO9780511813085

Caporaso, James A., \& Min-hyung Kim. 2009. The dual nature of European identity: subjective awareness and coherence. Journal of European Public Policy, 16(1), 19-42. https://doi.org/10.1080/13501760802453155

Crystal, David. 2008. A dictionary of linguistics and phonetics (6th ed.). Oxford: Blackwell Publishing.

European Commission. (2004). Many tongues, one family. Retrieved 3.04.2011 from http://ec.europa.eu/publications/booklets/move/45/en.pdf

European Commission. (2003). Promoting Language Learning and Linguistic Diversity: An Action Plan $2004-2006 \operatorname{COM}(2003) 449$ final. Retrieved 3.04 .2011 from http://ec.europa.eu/education/doc/official/keydoc/actlang/act_lang_en.pdf 
European Commission. (2005). Eurobarometer 64.2. Retrieved 3.04.2011 from http://ec.europa.eu/public_opinion/archives/eb/eb64/eb64_ee_exec.pdf

European Commission. (2010). Eurobarometer 73. Retrieved 3.04.2011 from http://ec.europa.eu/public_opinion/archives/eb/eb73/eb73_en.htm

European Commission. (2012). Eurobarometer 386. Retrieved 5.10.2014 from http://ec.europa.eu/public_opinion/archives/ebs/ebs_386_en.pdf

European Commission. (2018). Tourism Statistics. Retrieved 20.12.2018 from https://ec.europa.eu/eurostat/statistics-explained/index.php/Tourism_statistics

European Commission. (2018). Foreign Language Skills Statistics. Retrieved 20.12.2018 from https://ec.europa.eu/eurostat/statistics-explained/index.php/Tourism_statistics

European Commission. (2019). Mobile students from abroad enrolled by education level, sex and country of origin. Retrieved 30.10.2019 from https://appsso.eurostat.ec.europa.eu/nui/show.do?dataset=educ_uoe_mobs02\&lang=en

Dziubalska-Kolaczyk, Katarzyna, \& Joanna Przedlacka (Eds.). 2005. English Pronunciation Models: A Changing Scene. Bern: Peter Lang.

Félix-Brasdefer, Cesar J., and Andrew D. Cohen. 2012. Teaching Pragmatics in the Foreign Language Classroom: Grammar as a Communicative Resource. Hispania 95 (4): 650-669. https://doi.org/10.1353/hpn.2012.0124

Félix-Brasdefer, Cesar J. and Gerrard Mugford. 2017. (Im)politeness: Learning and Teaching. In: The Palgrave Handbook of Linguistic (Im)politeness, ed. by J. Culpeper, M. Haugh, and D.Z. Kádár, Basingstoke: Palgrave, 489-516. https://doi.org/10.1057/978-1-137-37508-7_19

Fraser, Bruce. 2010. Pragmatic Competence: a Case of Hedging. In: New Approaches to Hedging, ed. by G. Kaltenböck, W. Mihatsch, and S. Schneider. Bingley: Emerald, 15-34. https://doi.org/10.1163/9789004253247_003

Fuchs, Dieter, \& Hans-Dieter Klingemann and Andrea Schlenker-Fischer. 2011. Cultural diversity, European identity and the legitimacy of the EU: Summary and discussion. In: Cultural Diversity, European Identity and the Legitimacy of the EU, ed. by D. Fuchs, \& H.-D. Klingemann. Glos: Edward Elgar Publishing Limited, 247-262. https://doi.org/10.4337/9780857938084

Grundy, Sue, \& Lynn Jamieson. 2007. European Identities: From absent-minded citizens to passionate Europeans. Sociology, 41(4), 663-680. https://doi.org/10.1177/0038038507078919

Guibernau, Montserrat. 2011. The birth of a united Europe: on why the EU has generated a 'nonemotional' identity. Nations and Nationalism, 17(2), 302-315. https://doi.org/10.1111/j.14698129.2010.00477.x

Habermas, Jurgen. 1998. The Inclusion of the Other: Studies in Political Theory. Cambridge: Polity Press.

Haugh, Michael, \& Wei-Lin Melody Chang. 2015. Understanding Im/politeness Across Cultures: An Interactional Approach to Raising Sociopragmatic Awareness. International Review of Applied Linguistics 53 (4): 389-414. https://doi.org/10.1515/iral-2015-0018

Herrmann, Richard K., \& Marilynn B. Brewer. 2004. Identities and Institutions: Becoming European in the EU. In: Transnational identities: becoming European in the EU, ed. by R. K. Herrmann, Thomas Risse, Marilynn B. Brewer. Lenham, MD: Rowman \& Littlefield Publishers, pp. 1-22.

Hofstede, Geert. 1991. Cultures and Organizations: Software of the Mind. London, UK: McGrawHill.

Jenkins, Jennifer. 2000. The Phonology of English as an International Language. Oxford: Oxford University Press.

Kecskes, Istvan. 2013. Intercultural Pragmatics. Oxford: Oxford University Press. https://doi.org/10.1093/acprof:oso/9780199892655.001.0001

Klimczak-Pawlak, Agata. 2014. Towards the Pragmatic Core of English for European Communication. Springer. https://doi.org/10.1007/978-3-319-03557-4

Kostakopoulou, Dora. 2008. The Future Governance of Citizenship. Cambridge: Cambridge University Press. 
Li, Qiong, \& Marilynn B. Brewer. 2004. What Does It Mean to Be an American? Patriotism, Nationalism, and American Identity After 9/11. Political Psychology, 25(5), 727 - 739. https://doi.org/10.1111/j.1467-9221.2004.00395.x

Mar-Molinero, Clare, \& Patrick Stevenson. 2006. Language Policy in a Changing Europe. Language Policy, 5(3), 239-245. https://doi.org/10.1007/s10993-006-9024-5

Matsumoto, David, Jeffey LeRoux, \& Seung Hee Yoo. 2005. Emotion and intercultural communication. Kwansei Gakuin University Journal 99, 15-38.

Phillipson, Robert. 2006. Language policy and linguistic imperialism. In: An Introduction to Language Policy. Theory and method, ed. by T. Ricento. Oxford: Blackwell, 346-361.

Pichler, Florian. 2008. How Real is Cosmopolitanism in Europe? Sociology, 42(6), 1107-1126. https://doi.org/10.1177/0038038508096936

Risse, Thomas. 2004. Social Constructivism and European Integration. In: European Integration Theory, ed. by Antje Wiener \& Tanja A. Borzel, Oxfrod: Oxford University Press, 144-161.

Risse, Thomas. 2010. A Community of Europeans? London: Cornell University Press.

Savage, Michael, Gaynor Bagnall \& Brian Longhurst. 2005. Globalization and Belonging. London: Sage.

Rose, Kenneth R. Pragmatic Consciousness-Raising in an EFL Context. In: Pragmatics and Language Learning [Monograph Series], ed. by L. Bouton, vol. 5. Urbana- Champaign: Division of English as an International Language, University of Illinois, 52-63.

Schmidt, Richard. 1983. Interaction, Acculturation and the Acquisition of Communicative Competence. In: Sociolinguistics and Second Language Acquisition, ed. by N. Wolfson \& E. Judd. Rowley: Newbury House, 137-174.

Seidlhofer, Barbara. 2005. English as a lingua franca. ELT Journal, 59, 339-341. https://doi.org/10.1093/elt/cci064

Suzuki, Takao. 1978. Japanese and the Japanese. Tokyo: Kodansha.

Whorf, Benjamin Lee. 1956. Language, Thought and Reality: Selected Writings of Benjamin Lee Whorf. [ed. by JB Carroll]. Cambridge, MA: MIT Press.

Tatsuki, Donna \& Noel R. Houck (eds.). 2010. Pragmatics: Teaching Speech Acts. Alexandria: TESOL.

Wierzbicka, Anna. 1985. Different cultures, different languages, differents speech acts. Polish vs. English, Journal of Pragmatics 9, 145-178. https://doi.org/10.1016/0378-2166(85)90023-2

van Compernolle, R. (2014). Sociocultural Theory and L2 Instructional Pragmatics. New York: Multilingual Matters. https://doi.org/10.21832/9781783091409

Vertovec, Steven \& Robin Cohen (eds.). 2002. Conceiving Cosmopolitanism. Theory, Context, and Practice. Oxford: Oxford University Press. 